\title{
Multidisciplinary work promotes preventive medicine and health education in primary care: a cross-sectional survey
}

\author{
Ayelet Schor ${ }^{12^{*}}$ D, Lucia Bergovoy-Yellin ${ }^{3}$, Daniel Landsberger ${ }^{4}$, Tania Kolobov ${ }^{5,6}$ and Orna Baron-Epel ${ }^{7}$
}

\begin{abstract}
Background: Preventive medicine and health education are among the strategies used in coping with chronic diseases. However, it is yet to be determined what effect do personal and organizational aspects have on its' implementation in primary care.
\end{abstract}

Methods: A cross-sectional survey was conducted in order to assess and compare preventive medicine and health education activities in three types of primary care models: solo working independent physicians, nurse-physician collaborations and teamwork (nurses, dietitians and social workers working alongside a physician). Questionnaires were emailed to 1203 health professionals between September and November 2015, working at Maccabi Healthcare Services, the second largest Israeli healthcare organization.

Self-reported rates of health education groups conducted, proactive appointments scheduling and self-empowerment techniques use during routine appointments, were compared among the three models. Independent variables included clinic size as well as health professionals' occupation, health behaviors and training.

A series of multivariate linear regressions were performed in order to identify predictors of preventive medicine and health education implementation.

Computerized health records (CHR) validated our self-report data through data regarding patients' health behaviours and outcomes, including health education group registration, adherence to occult blood tests and influenza vaccinations as well as blood lipid levels.

Results: Responders included physicians, nurses, dietitians and social workers working at 921 clinics $(n=516$, response rate $=31 \%)$.

Higher rates of proactive appointments scheduling and health education groups were found in the Teamwork and Collaboration models, compared to the Independent Physician Model. Occupation (nurses and dietitians), group facilitation training and personal screening adherence were identified as preventive medicine and health education implementation predictors.

Group registration, occult blood tests, healthy population's well-controlled blood lipids as well as influenza vaccinations among chronically ill patients were all significantly higher in the Teamwork and Collaboration models, compared to the Independent Physician Model.

Conclusions: The Teamwork and Collaboration models presented higher rates of preventive medicine and health education implementation as well as higher rates of patients' positive health behaviours documented in these models. This suggests multidisciplinary primary care models may contribute to population's health by enhancing preventive medicine and health education implementation alongside health professionals' characteristics.

Keywords: Primary care model, Preventive medicine measures, Health education tools, Multidisciplinary practice

\footnotetext{
* Correspondence: a-schor@zahav.net.il

'School of Public Health, University of Haifa, Haifa, Israel

${ }^{2}$ Sde-varburg, Israel

Full list of author information is available at the end of the article
}

(c) The Author(s). 2019 Open Access This article is distributed under the terms of the Creative Commons Attribution 4.0 International License (http://creativecommons.org/licenses/by/4.0/), which permits unrestricted use, distribution, and reproduction in any medium, provided you give appropriate credit to the original author(s) and the source, provide a link to the Creative Commons license, and indicate if changes were made. The Creative Commons Public Domain Dedication waiver (http://creativecommons.org/publicdomain/zero/1.0/) applies to the data made available in this article, unless otherwise stated. 


\section{Background}

Non-adherence to medical and behavioral recommendations is common and is known to be affected by patients and physicians' characteristics alike [1-4].

Recent studies indicate that health professionals have the ability to improve patients' adherence using various behavioral tools and strategies for change [5-7].

One of the main strategies found to improve treatment processes and access to medical care, resulting in improved clinical outcomes [8-10] is multidisciplinary work. It is assumed that multidisciplinary collaborations increase the ability to accurately address a patient's individual needs, resulting in better adherence to treatment [11].

In order to achieve these goals, health professionals engage in health education in an attempt to educate and activate their patients. Health educations is defined as creating learning opportunities designed to allow patients to accept informed decisions and to promote positive health behaviors that would improve their health [12].

Health education utilizes a variety of tools designed to enhance patients' motivation and adherence.

One of these tools is the use of health education groups, where trained health professionals serve as group facilitators, guiding the participants in the acquisition of practical tools that promote desired behavioral changes.

These groups seem to be an effective preventive medicine tool, as participation helps in a variety of behavioral challenges such as weight loss, smoking cessation, and self-management of chronic illnesses [13, 14].

Another health education tool is the use of proactive appointments, initiated by the health provider rather than the patient. This allows health professionals the opportunity to focus on preventive medicine counseling, perform routine check-ups and use empowerment tools, such as motivational interviewing [15-17], in order to facilitate patients' adherence.

In spite of abundant supportive evidence indicating that the use of preventive medicine and health education tools reduces morbidity and mortality $[18,19]$, its' implementation may be complicated and ultimately depends on health professionals' motivation, affected by multi-level interpersonal, and organizational factors [20].

This study examined three primary care models implemented by Maccabi Healthcare Services (MHS). MHS is the second largest health maintenance organization (HMO) in Israel, with over two million clients, representing about a quarter of the country's population [21].

The basic primary care model, the Independent Physician Model, was developed when MHS was founded in 1940 [22]. Independent physicians work solo in private clinics. They are encouraged to achieve MHS' desired clinical outcomes, such as patients' vaccinations, and their income (per capita) is supplemented accordingly.
The second model examined is the Teamwork Model, based on the Chronic Care Model [23, 24] first implemented in MHS in 2005. Teamwork clinics employ various health professionals (physicians, nurses, dietitians and social workers). Composition of the teams vary among clinics, some include all four professions and others only two (a physician and one other health profession). The type of health professions, as well as the amount of weekly / monthly hours assigned to the team varies according to the population's needs as well as MHS' ability to supply specific demands. Thus, some clinics are based mostly on a physician and nurse with a few weekly / monthly hours of a dietitian and social worker, while others revolve around a physician and dietitian with a few nursing hours a week. Regardless of team composition, MHS expects all Teamwork clinics to apply multi-disciplinary work strategies, such as regular staff meetings, conducted in order to discuss patients' treatment. Teamwork strategies, however, are not monitored by MHS as a part of clinics' assessment conducted on a regular basis, so there is no objective data as to how common teamwork practices really are.

All Teamwork health professionals receive a monthly salary, independent of patients' outcomes, with the exception of physicians, who enjoy additional financial incentives similar to Independent physicians. As teamwork clinics are expected to focus on preventive medicine and patient self-management, health professionals affiliated with these clinics are prioritized when resources are allocated, for example when relevant training take place.

Attempting to provide different solutions to different needs and limited resources, in 2013, MHS began implementing the Collaboration Model. This Model stems from the Independent Physician Model and follows its financial model. Independent nurses collaborate with one to four adjacent primary care independent physicians who refer patients to their affiliated nurse when they see the need for a nurse's intervention, such as blood pressure monitoring, diabetes counseling, health education on other issues etc.On the other hand, when the independent nurses require consultations or see the need for treatment by physicians (like medication changes), they will refer the patient to their affiliated physician.

Patients choose their primary care physician and are mostly unaware of their affiliation to a specific primary care model. Accordingly, distributions of patients' main characteristics such as gender, age and morbidity levels, defined by Charlson score $[25,26]$ is mostly similar among the models. Most patients, in all models are males, Collaboration patients are a little younger with higher morbidity levels (significance mostly stemming from the large sample size).

Table 1 presents the organizational and patients' characteristics among the three primary care models. 
Table 1 Organizational and Patients' Characteristics among the Three Primary Care Models $s^{1,2}$

\begin{tabular}{|c|c|c|c|}
\hline & $\begin{array}{l}\text { Independent physician model } \\
n=92\end{array}$ & $\begin{array}{l}\text { Team model } \\
n=264\end{array}$ & $\begin{array}{l}\text { Collaboration model } \\
n=30\end{array}$ \\
\hline \multirow[t]{4}{*}{ Personnel } & \multirow[t]{4}{*}{ Physicians } & Physicians & \multirow[t]{2}{*}{ Physicians } \\
\hline & & Nurses & \\
\hline & & dietitians & \multirow[t]{2}{*}{ Nurses } \\
\hline & & Social-worker & \\
\hline \multirow[t]{2}{*}{ Clinic Ownership } & \multirow[t]{2}{*}{ Physician's clinic } & \multirow[t]{2}{*}{ MHS' clinic } & Physician's clinic \\
\hline & & & Nurse's clinic \\
\hline Supporting staff & Physicians' choice & MHS' allocation & Physicians' / Nurses' choice \\
\hline \multirow[t]{2}{*}{ Patients' Affiliation } & \multirow[t]{2}{*}{ Physician } & \multirow[t]{2}{*}{ Physician } & Physician \\
\hline & & & Nurse \\
\hline \multirow[t]{2}{*}{ Clinical Goals } & \multirow[t]{2}{*}{ Physicians' goals } & Physicians' goals & Physicians' goals \\
\hline & & No team goals & Nurses' goals \\
\hline \multirow[t]{6}{*}{ Fee Policies } & \multirow{6}{*}{$\begin{array}{l}\text { Per capita } \\
\text { Supplementation according } \\
\text { to defined outcomes achieved }\end{array}$} & Physicians Only & Physicians and Nurses \\
\hline & & Per capita & Per capita \\
\hline & & $\begin{array}{l}\text { Supplementation according to } \\
\text { defined outcomes achieved }\end{array}$ & $\begin{array}{l}\text { Supplementation according to defined } \\
\text { outcomes achieved }\end{array}$ \\
\hline & & All other professional & Nurses only \\
\hline & & Salary & \multirow{2}{*}{$\begin{array}{l}\text { Supplementation according to defined } \\
\text { counseling activities conducted (smoking } \\
\text { cessation counseling, diabetic guidance etc.) }\end{array}$} \\
\hline & & $\begin{array}{l}\text { No supplementation according } \\
\text { to defined outcomes achieved }\end{array}$ & \\
\hline Patients' Gender (Male) $)^{1,2}$ & 55.8 & 52.3 & 58.4 \\
\hline Patients' Age (Years) ${ }^{2,3}$ & $64.3 \pm 12$ & $64.2 \pm 12$ & $63.4 \pm 13$ \\
\hline Patients' Morbidity Levels 2,3,4 & $1.04 \pm 1.26$ & $1.08 \pm 1.27$ & $1.10 \pm 1.25$ \\
\hline
\end{tabular}

'Percentage within the model's population

${ }^{2} p<0.001$

${ }^{3}$ Mean \pm SD

${ }^{4}$ Charlson Score on December 31st, 2015

All health professionals (physicians, nurses, dietitians and social workers), regardless of the model they are affiliated with, are encouraged to acquire preventive medicine skills and implement relevant activities in their clinics. For that reason training is conducted within working hours and if not, health professionals are reimbursed for their time and training costs. In addition, professionals gain training points upon completion, granting them with additional income. Trained health professionals are free to conduct health education group counseling in all MHS' clinics and their income is supplemented accordingly.

Health education groups are available for all patients in multiple communal MHS facilities, regardless of the clinical model they belong to. This allows clinics that do not include trained health professionals but want to pursuit preventive medicine, to refer their patients to health education groups conducted in a nearby clinic, or to conduct one in their own clinic, guided by trained MHS health professionals, not affiliated with their own clinic.
Regretfully, while the benefits of preventative medicine and health education tools have been previously established [18, 27, 28], in reality, it is applied sporadically.

Moreover, its' implementation is not taken into account in routine clinic assessments, as other key components, such as patients' medication adherence or hospitalizations are.

Acknowledging that certain organizational aspects may affect the implementation of preventive medicine and health education tools, this study aimed to explore the use of such tools in various primary care models.

Our aim was to better understand what part do personal and organizational aspects play in the implementation of preventive medicine tools within the different primary care models implemented by MHS.

Since preventive medicine is highly encouraged by MHS in the Teamwork clinics, we assumed health professionals affiliated with the Teamwork Model would apply preventative medicine and health education tools more widely. 


\section{Methods}

A cross sectional survey was conducted between September and November 2015.

Questionnaires were emailed during 2015 to all health professionals (1203 physicians, nurses, dietitians, and

Table 2 Distribution of Clinic and Health Professionals' Personal Characteristics by Primary Care Model Affiliation ${ }^{a, b}$

\begin{tabular}{|c|c|c|c|c|c|}
\hline \multirow[t]{2}{*}{ Variable } & $\begin{array}{l}\text { Independent } \\
\text { physician model }\end{array}$ & $\begin{array}{l}\text { Team } \\
\text { model }\end{array}$ & $\begin{array}{l}\text { Collaboration } \\
\text { model }\end{array}$ & \multirow[t]{2}{*}{ Value $^{b}$} & $\begin{array}{l}p^{-} \\
\text {value }\end{array}$ \\
\hline & $n=92$ & $\begin{array}{l}n= \\
264\end{array}$ & $n=30$ & & \\
\hline
\end{tabular}

Clinic size

(No. of

patients) (\%)

$\begin{array}{llllll}\text { Up to } 400 & 10.6 & 6.2 & 3.3 & 18.35 & 0.001 \\ \text { 400-1000 } & 38.8 & 19.1 & 20 & & \\ \text { Over } 1000 & 50.6 & 74.7 & 76.7 & & \end{array}$

Personal

characteristics (\%)

Occupation

Physician 100

$28.8 \quad 40$

Nurse 0

36.960

Dietitian 0

Social 0

worker

Gender

$\begin{array}{ll}\text { Male } & 56.2 \\ \text { Female } & 43.8\end{array}$

$\begin{array}{ll}15.7 \quad 32.1 \\ 84.3 & 67.9\end{array}$

$84.3 \quad 67.9$

Participation

in patient

empowerment

training

Yes 15.7

No 843

$52.1 \quad 51.7$

$47.9 \quad 48.3$

Health

behaviors (\%)

\begin{tabular}{cccccc}
$\begin{array}{c}\text { Smoking } \\
\text { Yes }\end{array}$ & 3.8 & 2.9 & 10.7 & 4.03 & 0.13 \\
No & 96.2 & 97.1 & 89.3 & & \\
$\begin{array}{l}\text { Undergoing } \\
\text { egular } \\
\text { screening }\end{array}$ & & & & & \\
Yes & 75.0 & 84.3 & 78.6 & 3.46 & 0.17 \\
No & 25.0 & 15.7 & 21.4 & & \\
$\begin{array}{l}\text { Regular } \\
\text { physical } \\
\text { activity }\end{array}$ & & & & & \\
Yes & 73.7 & & & & \\
No & 26.3 & 61.8 & 41.2 & 4.31 & 0.11 \\
\hline
\end{tabular}

${ }^{\text {a Percent }}$

${ }^{\mathrm{b}}$ Chi-square/Fisher Test social workers) affiliated with one of the clinics included in this study, all of whom had been employed in the clinic for at least 12 months prior to the data collection date. All clinics who were operational for at least 12 months prior to the data collection date were included in our study. Respondents included 92 physicians from 594 Independent Physician clinics, 30 professionals from 52 Collaboration clinics, and 264 members of 273 Teamwork clinics, with 16,78 and $43 \%$ response rates respectively, overall response rate of $31 \%$. (Distribution of clinic and health professionals' personal characteristics by primary care model affiliation is presented in Table 2).

Questions were presented in Hebrew (translated to English by the authors for publication purposes). The questionnaires were completed anonymously via an automated system, preventing respondents' identification. Five weekly automatic reminders were sent to those who did not open the questionnaire link.

Data was extracted, processed and analyzed by MHS's Department of Health Services Research.

Respondents fully represented the health professionals affiliated with the clinic examined, with respect to gender, clinic size, and occupation, as presented in Table 3. Physicians and small clinics were under-represented, partly due to the fact that some health professionals, mainly physicians were affiliated with more than one clinic. While small clinics may differ in their ability to implement preventative medicine tools, as mentioned, MHS activities are available to all patients, regardless of the clinic they are affiliated with.

Regretfully, a low number of dietitians took part in the study. Since dietitians' work characteristics are more similar to those of nurses than to social workers, they were added to the nurses for analysis.

The dependent variables included three aspects representing the application of preventative medicine and health education tools in the clinic.

Health education groups implementation was examined by the reported frequency of running these groups in the clinic. Acknowledging the challenges of organizing health education groups, our aim here was to evaluate to what extent do health professionals implement this type of intervention in their clinics, regardless of the type of group conducted.

Therefore, the question was: "How often are smoking cessation groups / diabetes groups / group educational events, conducted in the clinic?" Responses ranged from $1=$ never to $4=3$ a year or more.

Proactive medicine was evaluated by the frequency of proactive appointments (a common organizational term) scheduled, reported by responses to the question: "How often do you schedule proactive appointments for your patients?" Responses ranged from 1 = never to $4=$ regularly.

The routine use of patient empowerment techniques was examined by the question: "How often 
do you use empowerment techniques during routine appointments?" Responses ranged from $1=$ never to $4=$ in most appointments.

Since these variables consisted of four categories and the answers did not distribute normally, they were dichotomized by combining the three lower scores into "low frequency to none", and "high frequency" represented by the highest score.

These three dependent variables were based on health professionals' self-report, as there is no existing objective quantitative data regarding these variables.

\section{Computerized data}

In order to support the self-reported data, we added computerized data extracted from MHS' computerized health records $(\mathrm{CHR})$ to our analysis.

We extracted data regarding 2015 prevalence rates of chronically ill patients in each primary care model as documented in MHS' chronic illness automatic registration system $[29,30]$, as well as registration rates to health education groups. This enabled us to objectively assess rates of registration to group counseling conducted.

We also examined a few health behavior outcomes documented in the CHR. This helped to gain a broader prospective and to assess whether activities implemented may indeed be associated with enhanced health outcomes. This data included the whole cohort of patients in Maccabi (Independent Physician Model $n=464,828$, Team Model $n=$ 269,844 and Collaboration Model $n=60,778$ ).

We chose health outcomes that are included in the Israeli quality indicators program, representing primary, secondary and tertiary prevention and may be improved with the support of trained health professionals. Among the healthy population (MHS members not in one or more of the chronically ill registries), we examined rates of conducting occult blood tests and well-controlled lipid levels. Influenza vaccination rates among diabetic patients as well as heart diseases and high bloodpressure patients were also examined. (Yes / No for all variables). These health outcomes are defined by the Israeli Quality Health Indicators Plan, shown to significantly affect various health behaviors as well as chronically ill patients' health status [12, 31].

The independent variables consisted of the respondents' personal characteristics as well as clinic characteristics.

\section{Clinic characteristics}

Included the type of model (Independent Physician / Teamwork / Collaboration) and clinic size (small $<400$ patients, medium $=400-1000$ patients, large $>1000$ patients).

\section{Personal characteristics}

Gender, occupation and personal health behaviors (smoking, regular physical activity, and adhering to relevant health screening).

\section{Training}

Professional's participation in health education training (motivational interviewing / smoking cessation counseling / group facilitation), as well as time passed since completion of this training (1-6 months, 7-12 months, 13-24 months, over 24 months).

Training data was analyzed as an ordinal variable. Each type of training was given a value reflecting the

Table 3 Respondents versus MHS' health professionals affiliated with the three Primary Care Models

\begin{tabular}{|c|c|c|c|c|c|c|c|}
\hline & & & \multicolumn{2}{|c|}{ Gender } & \multicolumn{3}{|c|}{ Clinic size } \\
\hline & & & Male & Female & Small & Medium & Large \\
\hline \multirow{2}{*}{\multicolumn{2}{|c|}{ Independent Physician Model }} & Percentage among respondents & 57 & 43 & 9.8 & 37 & 53.3 \\
\hline & & Percentage among $\mathrm{MHS}^{\prime}$ employees & 62.6 & 37.4 & 16.3 & 19.9 & 53.8 \\
\hline \multirow[t]{8}{*}{ Team model } & Physicians & Percentage among respondents & 55.6 & 44.4 & 1.3 & 26.7 & 72 \\
\hline & & Percentage among MHS' employees & 56.2 & 43.8 & 57.1 & 26.2 & 17 \\
\hline & Nurses & Percentage among respondents & 4.7 & 95.3 & 1.1 & 5.4 & 93.5 \\
\hline & & Percentage among $\mathrm{MHS}^{\prime}$ employees & 2.8 & 96.2 & 3.6 & 47.8 & 60.7 \\
\hline & Dietitian & Percentage among respondents & 2.2 & 97.8 & 24 & 34 & 42 \\
\hline & & Percentage among $\mathrm{MHS}^{\prime}$ employees & 3.7 & 96.3 & 16.7 & 28.7 & 54.6 \\
\hline & Social Worker & Percentage among respondents & 16.7 & 83.3 & 3.4 & 13.8 & 82.8 \\
\hline & & Percentage among $\mathrm{MHS}^{\prime}$ employees & 19.3 & 80.7 & 4.2 & 11.4 & 84.3 \\
\hline \multirow{2}{*}{\multicolumn{2}{|c|}{ Collaboration Model }} & Percentage among respondents & 11.8 & 88.2 & 5.6 & 27.8 & 66.7 \\
\hline & & Percentage among MHS' employees & 5.2 & 94.8 & 24.2 & 29.5 & 46.3 \\
\hline
\end{tabular}


time elapsed since completion $(1=$ no training, $2=1-6$ months, $3=7-24$ month, $4=$ over 24 months).

\section{Statistical analysis}

The data were analyzed using the statistical program for Health and Welfare Science for Windows (SPSS, version 22.0, Chicago, IL, USA). Descriptive data analysis included range, mean and standard deviation for continuous variables, and frequency and percentage for categorical variables. Personal characteristics were analyzed using Chisquare and Fisher tests.

Comparisons of means regarding health education application among the three models were performed using Kruskal-Wallis tests.

Between groups comparisons were conducted in order to assess between which two groups differences were significant. Bonferroni for distribution of clinic and health professionals' characteristics as well as for preventive medicine implementation and Pairwise contrasts for patients' health results.

Logistic regression models were conducted in order to identify predictors of health education implementation.

The significance for all the statistical tests was set to 0.05 .

\section{Results}

The clinic and personal characteristics are presented in Table 2.

The majority of respondents affiliated with the Teamwork and Collaboration models were women, while in the Independent Physician Model most were men $(p<0.001)$.

As a whole, the health professionals reported high rates of positive health behaviors, and the differences among the models were not statistically significant.

Reported rates of health education training were similar in the Teamwork and the Collaboration models (about $52 \%$ ), as opposed to only $16 \%$ in the Independent Physician Model $(p<0.001)$.

Table 4 presents the average scores of implementing preventative medicine and health education tools in the three models.

Overall, respondents from the multidisciplinary models (Collaboration and Teamwork models) reported similarly higher rates of proactive medicine and health education tools implementation compared with the Independent Physician Model.

The multidisciplinary models reported significantly higher rates of health education group counseling conducted in the clinics (mean scores of 3.2, 3.1 and 1.7 for the Teamwork, Collaboration and Independent Physician models respectively $p<0.001$ ).

Registration to health education group counseling among chronically ill patients was higher in the multidisciplinary models. Registration rates ranged from 2.19\% in the Independent Physician Model $(n=4596 /$
209,385), through $2.29 \%(n=3436 / 149,412)$ in the Teamwork Model, to $3.05 \%(n=764 / 24,995)$ in the Collaboration Model $(p<0.001)$.

Rates of proactive appointment scheduling in the clinic were also significantly higher in the multidisciplinary models compared with the Independent Physician Model (mean score of 3.8 and 3.7 and 3.0 for the Collaboration, Teamwork and Independent Physician models respectively, $p<0.001$ ).

No significant differences were observed between the models regarding the use of empowerment techniques $(p=0.17)$. However, they were higher in the multidisciplinary models.

Variables that may predict the implementation of proactive medicine tools were identified through multivariable linear regression models.

Table 5 presents predictors of preventative medicine and health education tools implementation.

The type of primary care model significantly predicted health education groups counseling conducted in the clinic. Respondents from the Teamwork Model and the Collaboration Model were much more likely to conduct group counseling activities in the clinics than those of the independent physician model $(\mathrm{OR}=6.1,95 \% \mathrm{CI} 2.63-$ 14.13 and $\mathrm{OR}=4.3,95 \% \mathrm{CI} 1.38-13.57$ respectively). The Teamwork Model was not significantly different from the Collaboration Model and both were significantly different from the Independent physician Model $(p<0.001)$.

Another significant predictor of group-counseling activities was the type of occupation. Nurses and dietitians were twice as likely to conduct group counseling, compared to physicians $(\mathrm{OR}=2.08,95 \% \mathrm{CI} 1.09-3.95)$.

Significant predictors of proactive appointment scheduling included affiliation with the Teamwork Model $(\mathrm{OR}=2.1,95 \% \mathrm{CI} 1.04-4.19)$, occupation, namely nurses and dietitians $(\mathrm{OR}=28.46,95 \% \mathrm{CI} 8.58-94.4)$ and training, specifically smoking cessation training $(\mathrm{OR}=3.95$, 95\%CI 1.15-13.53). The Teamwork Model was not significantly different from the Collaboration Model and both were significantly different from the Independent physician Model $(p<0.001)$.

Significant predictors for the use of patient empowerment techniques during routine appointments included group facilitation training and health professionals' adherence to regular screening $(\mathrm{OR}=2.77,95 \% \mathrm{CI} 1.30$ $5.92 ; \mathrm{OR}=2.29,95 \% \mathrm{CI} 1.14-4.49$ respectively).

Rates of most patients' health outcomes we examined were significantly higher in the Teamwork and Collaboration models (presented in Table 6).

The only variable in which the Independent Physician Model presented similar results to those of the Teamwork Model was the influenza vaccination among diabetic patients (46.01 and $46.2 \%$ respectively). However, the Collaboration model presented significantly higher 
Table 4 Average Score of Preventive Medicine Tools Implementation among the Models ${ }^{a}$ b, c

\begin{tabular}{|c|c|c|c|c|c|c|c|c|c|c|c|}
\hline & \multicolumn{3}{|c|}{$\begin{array}{l}\text { Independent } \\
\text { Physician model } \\
n=92\end{array}$} & \multicolumn{3}{|c|}{$\begin{array}{l}\text { Teamwork model } \\
n=264\end{array}$} & \multicolumn{3}{|c|}{$\begin{array}{l}\text { Collaboration } \\
\text { model } n=30\end{array}$} & \multirow{3}{*}{$\mathrm{F}$} & \multirow{3}{*}{ Sig. } \\
\hline & \multirow[t]{2}{*}{ mean } & \multicolumn{2}{|c|}{ C.I $95 \%$} & \multirow[t]{2}{*}{ mean } & \multicolumn{2}{|c|}{ C.I 95\% } & \multirow[t]{2}{*}{ mean } & \multicolumn{2}{|c|}{ C.I 95\% } & & \\
\hline & & Low. & Up. & & Low. & Up. & & Low. & Up. & & \\
\hline $\begin{array}{l}\text { Conduct group counseling activities ( } 1=\text { never to } 4=\text { three a year or } \\
\text { more) }\end{array}$ & 1.7 & 1.44 & 1.89 & 3.2 & 3.02 & 3.28 & 3.1 & 2.71 & 3.50 & 66.844 & $\begin{array}{l}p< \\
0.001\end{array}$ \\
\hline Schedule proactive appointments ( $1=$ never to $4=$ regularly $)$ & 3.0 & 2.82 & 3.25 & 3.7 & 3.62 & 3.78 & 3.8 & 3.56 & 3.95 & 27.687 & $\begin{array}{l}p< \\
0.001\end{array}$ \\
\hline $\begin{array}{l}\text { Use of empowerment techniques during routine appointments ( } 1=\text { never } \\
\text { to } 4=\text { in most appointments) }\end{array}$ & 3.0 & 2.81 & 3.23 & 3.2 & 3.09 & 3.30 & 3.3 & 3.02 & 3.60 & 1.773 & 0.17 \\
\hline
\end{tabular}

rates of diabetic influenza vaccination compared with those of the Independent Physician Model $(p<0.018)$.

\section{Discussion}

This study aimed at identifying factors that support or hinder the implementation of preventive medicine and health education tools in various primary care models.

Combining health professionals' self-report with computerized objective data enabled us to gain insights regarding personal and organizational aspects that are associated with the implementation of preventive medicine and health education tools. While this study examined MHS, our findings are likely to be relevant to other Israeli HMOes, as well as other countries implementing similar primary care models.

Our results found that the health professionals affiliated with the multidisciplinary models engaged in more training and implementation of preventive medicine and health education tools compared to those affiliated with the Independent Physician Model. More specifically, significantly higher rates of proactive appointments scheduling and health education groups were found in the Teamwork and Collaboration models, compared to the Independent Physician Model.

This confirmed our basic hypothesis that Teamwork enhances the implementation of preventive medicine and supports previous research that demonstrated Teamwork to yield better patient adherence as well as improved clinical outcomes [10].

To our surprise, while the Collaboration Model and the Independent Physician Model operate under similar organizational approaches, results presented by the Collaboration Model resembled those of the Teamwork Model.

The significant predictors of preventive medicine implementation we identified can be divided into two mutually interactive levels: the personal level (health professionals) and the organizational level (MHS). These multi-leveled interactions were previously established by DiClemente et.al. as influencing behavioral choices among employees, in our case, their choice to implement preventive medicine tools [20].

The significant Personal level factors we identified included health behaviors (namely adhering to regular health screening), training and occupation, all identified as relevant in previous studies [3, 4, 15]. We found nurses were 28.5 more times likely to schedule proactive appointments. This is in line with previous studies demonstrating the significance of the nursing profession in proactive medicine within primary care [17]. Moreover, preventative medicine is traditionally conducted primarily by nurses in Israeli practices. This is well described in a recent Israeli survey that found physicians perceiving nurses as contributing to practice quality and as sharing the responsibility for quality of care [32].

The organizational level factors demonstrated the significance of the type of primary care model manifested by different combinations of health professionals affiliated with the clinics, as well as different policies such as resources allocated or fee, varied among the models and the professions. The significance of these aspects is addressed later.

Relevant training was highly effective as we did find that primary care models with a higher percentage of trained health professionals implemented more preventive medicine and health education tools. Moreover, the more experienced the professionals were in group facilitation, the more likely they were to use empowering techniques in their routine appointments.

On the other hand, high rates of proactive appointment scheduling and health education group registration in the Independent Physicians' Model were seemingly contradictory to the low training levels reported by this model's respondents.

This may be attributed to the fact that physicians affiliated with this model do not have nurses to depend upon in encouraging patients to participate in relevant activities, as commonly done in Israeli multidisciplinary teams [32], prompting them to do so on their own. 
Table 5 Logistic Regression Analysis Presenting Predictors of Preventative Medicine Implementation in the Clinics ${ }^{\mathrm{a}, \mathrm{b}}$

\begin{tabular}{|c|c|c|c|c|c|}
\hline \multirow[t]{2}{*}{ Variable } & \multirow[t]{2}{*}{ Category } & \multirow[t]{2}{*}{ OR } & \multicolumn{2}{|c|}{$95 \%$ C.I. } & \multirow[t]{2}{*}{ Sig. } \\
\hline & & & Lower & Upper & \\
\hline \multicolumn{6}{|c|}{ Conducting health education group counseling in the clinic } \\
\hline \multirow[t]{3}{*}{ Primary care model type } & Independent Physician & 1.000 & & & \\
\hline & Collaboration & 4.33 & 1.38 & 13.57 & 0.01 \\
\hline & Teamwork & 6.09 & 2.63 & 14.13 & $p<0.001$ \\
\hline \multirow[t]{2}{*}{ Occupation } & Physician & 1.000 & & & \\
\hline & Nurse + Dietitians & 2.08 & 1.09 & 3.95 & 0.02 \\
\hline \multirow[t]{2}{*}{ Training } & Group facilitation & 0.77 & 0.36 & 1.63 & 0.50 \\
\hline & Smoking cessation & 2.09 & 0.79 & 5.52 & 0.13 \\
\hline Health behaviors & Adhering to regular screening & 1.18 & 0.59 & 2.35 & 0.63 \\
\hline \multicolumn{6}{|c|}{ Scheduling proactive appointments } \\
\hline \multirow[t]{3}{*}{ Primary care model type } & Independent Physician & 1.000 & & & \\
\hline & Collaboration & 0.77 & 0.21 & 2.74 & 0.68 \\
\hline & Teamwork & 2.09 & 1.04 & 4.19 & 0.03 \\
\hline \multirow[t]{2}{*}{ Occupation } & Physician & 1.000 & & & \\
\hline & Nurse + Dietitians & 28.46 & 8.58 & 94.42 & $p<0.001$ \\
\hline \multirow[t]{2}{*}{ Training } & Group facilitation & 1.52 & 0.58 & 3.94 & 0.38 \\
\hline & Smoking cessation & 3.95 & 1.15 & 13.53 & 0.02 \\
\hline Health behaviors & Adhering to regular screening & 0.95 & 0.47 & 1.93 & 0.90 \\
\hline \multicolumn{6}{|c|}{ Using patient empowerment techniques in routine appointments } \\
\hline \multirow[t]{3}{*}{ Primary care model type } & Independent Physician & 1.000 & & & \\
\hline & Collaboration & 0.63 & 0.21 & 1.81 & 0.39 \\
\hline & Teamwork & 0.53 & 0.26 & 1.07 & 0.08 \\
\hline \multirow[t]{2}{*}{ Occupation } & Physician & 1.000 & & & \\
\hline & Nurse + Dietitians & 1.77 & 0.92 & 3.42 & 0.08 \\
\hline \multirow[t]{2}{*}{ Training } & Group facilitation & 2.76 & 1.29 & 5.92 & 0.009 \\
\hline & Smoking cessation & 0.79 & 0.30 & 2.10 & 0.64 \\
\hline Health behaviors & Adhering to regular screening & 2.29 & 1.14 & 4.59 & 0.01 \\
\hline
\end{tabular}

${ }^{\text {aT }}$ The table presents only significant predictors

${ }^{b}$ Variables included in the linear regression and were not significant: clinic size, gender, social worker occupation, motivational interview training, regular physical activity, smoking

The use of empowerment techniques during routine appointments may be influenced by personal level factors, such as positive attitudes towards patient empowerment, while organizational factors such as clinic space do not play a role in the use of this tool. This may explain why we found the three models did not differ where the use of empowerment techniques in routine appointments was concerned.

Various fee policies implemented by MHS may have also influenced the decision to apply preventive medicine tools. However, while financial incentives have been found to be effective in improving processes of care and achieving targeted outcomes [33] our results challenge this perception.

The Independent Physician and the Collaboration models, both enjoying financial incentives, presented significantly different results regarding preventive medicine.
Furthermore, in the Teamwork model, respondents reported high rates of preventive medicine and health education tools implementation despite the lack of incentives for health professionals, other than the physicians. Moreover, Teamwork nurses and dietitians were strongly associated with higher levels of group counseling and proactive appointment scheduling. This implies that financial incentives may not necessarily promote the implementation of preventive medicine tools and its' specific effect require further investigation.

Result concerning preventive medicine implementation as well as patients' health results, may be associated with the different sample sizes among the primary care models. In between two groups differences regarding patients' health outcomes may be attributed to large sample sizes. Never the less, the fact that Collaboration 
Table 6 Rates of Health Behaviours among the Three Primary Care Models ${ }^{a}$

\begin{tabular}{|c|c|c|c|c|c|}
\hline$\underline{\text { Variables }}$ & Independent physician model & Team model & Collaboration model & Value $^{\mathrm{b}}$ & $p$-value \\
\hline \multicolumn{6}{|l|}{ Healthy Population } \\
\hline & $n=464,828$ & $n=269,844$ & $n=60,778$ & & \\
\hline Occult Blood Test & 60.0 & 61.6 & 61.4 & 90.51 & $p<0.001$ \\
\hline Well-Controlled Lipid Levels ${ }^{c}$ & 91.1 & 91.6 & 91.5 & 210.11 & $p<0.001$ \\
\hline \multicolumn{6}{|l|}{ Diabetic Population } \\
\hline & $n=51,861$ & $n=37,455$ & $n=6006$ & & \\
\hline Influenza Vaccination & 55.2 & 56.0 & 60.4 & 58.04 & $p<0.001$ \\
\hline \multicolumn{6}{|l|}{ Heart Diseases Population } \\
\hline & $n=37,036$ & $n=25,239$ & $n=4509$ & & \\
\hline Influenza Vaccination & 57.9 & 59.1 & 63.3 & 49.71 & $p<0.001$ \\
\hline \multicolumn{6}{|l|}{ High Blood-Pressure Population } \\
\hline & $n=120,349$ & $n=86,629$ & $n=14,461$ & & \\
\hline Influenza Vaccination & 46.0 & 46.1 & 50.2 & 96.19 & $p<0.001$ \\
\hline
\end{tabular}

${ }^{\text {a }}$ ercent among target population

${ }^{\mathrm{b}}$ Chi-square

c Among patients who underwent lipid levels check-ups during 2015

Model presented similar results to that of the Teamwork Model, which requires considerable organizational investment, raises the need to reassess organizational policies regarding these models. Fee policies, personnel allocation etc. should be re-evaluated in order better utilize existing resources while maintaining optimal patients' health outcomes.

Organizational support has been proven essential to conduct adequate teamwork [34] and previous research has indicated that defining unit outcomes, as well as rewarding all members accordingly, may help engage all members in the process and enhance interdisciplinary collaborations [35].

Furthermore, adding the use of preventive medicine and health education to the clinics' routine assessments may affirm the organizational support of such tools and help enhance its implementation. All these may help encourage all team members to make better use of preventive medicine and health education. Until such a time, as important as personal characteristics, training, or type of primary care models are, they may not sufficiently motivate health professionals to engage in preventive medicine more extensively.

This study had a few limitations.

The response rate was not high. Physicians' underrepresentation may present a partial picture regarding preventative medicine implementation in their clinics. Since responding physicians represented all of MHS' physicians with respect to gender and clinic size (with the exception of under-representation of small clinics, which is less relevant, as discussed in the methods section) we feel this bias did not profoundly flaw our study's conclusions.
In addition, assessing rates of preventive medicine and health education tools implementation based on selfreport could be biased by employees' tendency to overreport activities preformed due to the need to better fit their own professional perception, or to meet MHS's expectations. The automated questionnaire system was used to minimize this aspect as much as possible and further validation was gained through the CHR data, found to support our findings.

The Collaboration Model's sample size was vastly different from the other two models. This difference is representative of MHS clinics and does not impair statistical conclusions deduced in this study.

\section{Conclusions}

This study has provided new insights regarding variables affecting implementation of preventive medicine and health education tools in primary care. We found multidisciplinary models to be associated with higher levels of these tools' implementation. While these results were based on health professionals self-report, it was also strongly supported by objective organizational computerized data.

Although the organizational approach to the Collaboration Model resembles that of the Independent Physicians, in terms of preventive medicine application, this model resembled the Teamwork model. This indicates that multidisciplinary support may help promote higher rates of preventive medicine and health education implementation as well as better patients' health behaviors.

Supporting professionals' training as well as acquiring collaboration skills is essential and may help promote the implementation of the tools acquired. 
Our findings may assist health organizations and policy-makers in modifying practice attributes to enhance preventive medicine and health education implementation in primary care.

Further examination of patients' health outcomes in future studies, may ascertain the link between preventative medicine and health education implementation and patients' clinical outcomes in the various models.

\section{Abbreviations}

CHR: Computerized Health Records; HMO: Healthcare Maintenance Organization; MHS: Maccabi Healthcare Services; OR: Odds Ratio

\section{Acknowledgements}

Not applicable.

\section{Authors' contributions}

AS - Initiated the study, formulated the questionnaires, interpreted the data and was the major contributor in writing the manuscript. LBY - Extracted and analyzed the obtained data. DL - Provided organizational and professional support, as Maccabi Health Services' delegate. TK - Assisted in advanced statistical analysis and interpretation of the obtained data. OBE - Assisted in formulating the study and consolidating the final coherent message and manuscript. All authors read and approved the final manuscript.

\section{Funding}

This work was supported by the Israeli National Institute for Health Policy Research (Grant No. 2015/24/R). The institute was not involved in any aspect of the study or its publication.

\section{Availability of data and materials}

The data that support the findings of this study are available from Maccabi Health Services' department of Health Services Research, but restrictions apply to the availability of these data, which were used under license for the current study, and so are not publicly available. Data are however available from the authors upon reasonable request and subject to MHS' permission.

\section{Ethics approval and consent to participate}

The study was approved by the MHS ethics committee (reference No. 2015006). Participants filled a computerized questionnaire, indicating their consent to take part in this study.

\section{Consent for publication}

This manuscript does not contain data from any individual person, therefor this is not applicable.

\section{Competing interests}

The authors declare that they have no competing interests.

\begin{abstract}
Author details
'School of Public Health, University of Haifa, Haifa, Israel. ${ }^{2}$ Sde-varburg, Israel. ${ }^{3}$ Department of Health Services Research and Health Economics, Maccabi Healthcare Services, 27 Ha'Mered Street, Tel Aviv, Israel. ${ }^{4}$ Maccabi Healthcare Services, 3 Ha'Netsach Street, Ramat-Hasharon, Israel. ${ }^{5}$ School of Education, Bar-llan University, Ramat Gan, Israel. ${ }^{6}$ Qyriat Bialik, Israel. ${ }^{7}$ School of Public Health, University of Haifa, 199 Abba khoushy Mount Carmel, 3498838 Haifa, Israel.
\end{abstract}

Received: 5 November 2018 Accepted: 23 May 2019

Published online: 06 June 2019

\section{References}

1. Wilf-Miron R, et al. "Disparities in diabetes care: role of the patient's sociodemographic characteristics," (in eng). BMC Public Health. 2010;10:729.

2. Koh HK, Brach C, Harris LM, Parchman ML. A proposed 'Health literate care Model' would constitute a systems approach to improving patients' engagement in care. Health Aff. 2013;32:357-67.
3. Frank $E$, Dresner $Y$, Shani M, Vinker S. "The association between physicians' and patients' preventive health practices," (in eng). Can Med Assoc J. 2013;185(8):649-53.

4. Oberg EB, Frank E. Physicians' health practices strongly influence patient health practices. J R Coll Physicians Edinb. 2009;39(4):290-1 National Institutes of Health Public Access.

5. Vijan S, Sussman JB, Yudkin JS, Hayward RA. "Effect of patients' risks and preferences on health gains with plasma glucose level lowering in type 2 diabetes mellitus," (in eng). JAMA Intern Med. 2014;174(8):1227-34.

6. Marcum ZA, Sevick MA, Handler SM. "Medication nonadherence: a diagnosable and treatable medical condition," (in eng). Jama. 2013;309(20):2105-6.

7. Parchman ML, Zeber JE, Palmer RF. "Participatory decision making, patient activation, medication adherence, and intermediate clinical outcomes in type 2 diabetes: a STARNet study," (in eng). Ann Fam Med. 2010;8(5):410-7.

8. Okun S, Schoenbaum SC, Ricciardi R, Strasser D, Wynia MK, et al. In: ResearchGate: the national academy of science, editor. Patients and health care teams forging effective partnerships; 2014.

9. Brennan SE, Bosch M, Buchan H, Green SE. "Measuring team factors thought to influence the success of quality improvement in primary care: a systematic review of instruments," (in eng). Implement Sci. 2013;8:20.

10. Chris M. Primary care team of the year: saving money and improving care. Br Med J. 2014;10:348.

11. Mickan SM. "Evaluating the effectiveness of health care teams," (in eng). Aust Health Rev. 2005;29(2):211-7.

12. Beaulieu MD, et al. "[Development of quality of care indicators to support chronic disease management]," (in fre). Sante Publique. 2015; 27(1 Suppl):S67-75.

13. Benyamini Y, Geron R, Steinberg DM, Medini N, Valinsky L, Endevelt R. "A structured intentions and action-planning intervention improves weight loss outcomes in a group weight loss program," (in eng). Am J Health Promot. 2013;28(2):119-27.

14. Ginsberg G. Cost-effectivness analysis of intervention programs targeted to reduce the burden of smoking-related morbidity. Israel: Smokler institute for Health Policy Research; 2010.

15. Rosenbek Minet LK, Wagner L, Lønvig EM, Hjelmborg J, Henriksen JE. "The effect of motivational interviewing on glycaemic control and perceived competence of diabetes self-management in patients with type 1 and type 2 diabetes mellitus after attending a group education programme: a randomised controlled trial," (in eng). Diabetologia. 2011;54(7):1620-9.

16. Greene J, Hibbard JH, Alvarez C, Overton V. "Supporting patient behavior change: approaches used by primary care clinicians whose patients have an increase in activation levels," (in eng). Ann Fam Med. 2016;14(2):148-54.

17. Hogg $W$, et al. "Health promotion activity in primary care: performance of models and associated factors" (in eng). Open Med. 2009;3(3):e165-73.

18. Narasimhan K. "General health checks for reducing morbidity and mortality" (in eng). Am Fam Physician. 2013;88(7):432-3.

19. Márk L, Dani G. "[Diabetic dyslipidaemia and the atherosclerosis]," (in Hun). Orv Hetil. 2016;157(19):746-52.

20. DiClemente RJE, Crosby RA, Kegler MC, editors. Emerging theories in health promotion practice and research. 2nd ed. San Francisco: Wiley; 2009. p. 583.

21. Barak L. Barzilay D. Summary report on HMOs' activities 2015 (Hebrew); 2016. www.health.gov.il/publicationsfiles/dochhashvaatui2015.pdf.

22. Rivlin A. A private level medicine in the HMO (Hebrew). Israel: Maccabi health services; 1991.

23. Bodenheimer T, Wagner EH, Grumbach K. "Improving primary care for patients with chronic illness: the chronic care model, Part 2," (in eng). Jama. 2002;288(15):1909-14.

24. Kadu MK, Stolee P. "Facilitators and barriers of implementing the chronic care model in primary care: a systematic review," (in eng). BMC Fam Pract. 2015;16(1):12.

25. Charlson ME, Pompei P, Ales KL, MacKenzie CR. "A new method of classifying prognostic comorbidity in longitudinal studies: development and validation," (in eng). J Chronic Dis. 1987;40(5):373-83.

26. Yurkovich M, Avina-Zubieta JA, Thomas J, Gorenchtein M, Lacaille D. "A systematic review identifies valid comorbidity indices derived from administrative health data," (in eng). J Clin Epidemiol. 2015;68(1):3-14.

27. Hoffmann TC, et al. "Prescribing exercise interventions for patients with chronic conditions," (in eng). CMAJ. 2016;188(7):510-8.

28. Naci H, loannidis JP. "comparative effectiveness of exercise and drug interventions on mortality outcomes: metaepidemiological study," (in eng). BMJ. 2013;347:f5577. 
29. Shalev V, Chodick G, Goren I, Silber H, Kokia E, Heymann AD. "The use of an automated patient registry to manage and monitor cardiovascular conditions and related outcomes in a large health organization," (in eng). Int J Cardiol. 2011:152(3):345-9.

30. Chodick G, Heymann AD, Shalev V, Kookia E. "The epidemiology of diabetes in a large Israeli HMO," (in eng). Eur J Epidemiol. 2003;18(12):1143-6.

31. Calderon-Margalit $\mathrm{R}$, et al. "Trends in the performance of quality indicators for diabetes care in the community and in diabetes-related health status: an Israeli ecological study" (in eng). Isr J Health Policy Res. 2018;7(1):10.

32. Nissanholtz-Gannot R, Goldman D, Rosen B, Kay C, Wilf-Miron R. "How do primary care physicians perceive the role of nurses in quality measurement and improvement? The Israeli story," (in eng). Front Public Health. 2016;4:124.

33. Flodgren G, Eccles MP, Shepperd S, Scott A, Parmelli E, Beyer FR. "An overview of reviews evaluating the effectiveness of financial incentives in changing healthcare professional behaviours and patient outcomes," (in eng). Cochrane Database Syst Rev. 2011;7(7):CD009255.

34. Taplin SH, Foster MK, Shortell SM. "Organizational leadership for building effective health care teams," (in eng). Ann Fam Med. 2013;11(3):279-81.

35. Leasure EL, et al. "There is no " $\mathrm{i}$ " in teamwork in the patient-centered medical home: defining teamwork competencies for academic practice," (in eng). Acad Med. 2013;88(5):585-92.

\section{Publisher's Note}

Springer Nature remains neutral with regard to jurisdictional claims in published maps and institutional affiliations.

Ready to submit your research? Choose BMC and benefit from:

- fast, convenient online submission

- thorough peer review by experienced researchers in your field

- rapid publication on acceptance

- support for research data, including large and complex data types

- gold Open Access which fosters wider collaboration and increased citations

- maximum visibility for your research: over $100 \mathrm{M}$ website views per year

At $\mathrm{BMC}$, research is always in progress.

Learn more biomedcentral.com/submissions 